\title{
SOCIOLOGY OF HEALTH AND SANITATION IN ANINI, DIBANG VALLEY DISTRICT, ARUNACHAL PRADESH: A CASE STUDY
}

\section{BIKASH BAGE}

Department of Sociology, Rajiv Gandhi University, Rono Hills, Doimukh, Arunachal Pradesh, India

\begin{abstract}
To live a healthy life, people must practice proper hygiene and sanitation. This would also include proper understanding of the value of potable drinking water, proper nutrient intake and physical exercise. There are various research works being done on the relationship between health status of the people and sanitation practices. The underpinning of the present study emphasizes on the necessary aspects of how to study water condition, sanitation status and hygiene practices of people at household and community levels, both in urban and rural areas. Sanitation can be seen as the policy and practice of protecting health through hygienic measures. In the view of World Health Organization, sanitation generally refers to the provision of facilities and services for the safe disposal of human urine and faeces. It has been realized that improving sanitation is known to have a significant impact on health both in households and across communities (WHO, 2007).

KEYWORDS: Health and Sanitation, Water
\end{abstract}

Received: Jun 09, 2020; Accepted: Jun 29, 2020; Published: Sep 19, 2020; Paper Id.: IJMPERDJUN20201346

\section{INTRODUCTION}

Water, sanitation and hygiene are of immense importance to be addressed in the realm of livelihood and health status for a country's human development index. Most of the developing countries stressed with slum areas and ever growing population lack the basic structure of sanitation, due to lack of education among the dwellers and paucity of funding patterns from the government. This has led to the absence of sanitation facility, deliberate spread of communicable diseases and eventually high mortality rate in the community.

In addition, poverty plays a decisive role to bridge the gap between health status and sanitation. The provision of clean drinking water, sanitation facilities, good sanitation practices and clean environment are vital in improving the health and quality of life of people in the community which may be abundantly available due to poverty. According to WHO, 80 percent of disease in India are related to unsafe drinking water, lack of hygiene and sanitation practices among the people, provision of livelihood facilities and lack of essential advanced human life technology. It is estimated that about 60 per cent of the total medical expenses incurred by a family are spent for treatment of common diseases caused due to unsafe and poor environmental sanitation.

Behavioural pattern of people can have affected the health of an individual. For instance, smoking, over use of alcohol, use of drugs, tobacco products etc. have direct bearing on the health status which in long run can be fatal and life threatening. Common community behaviour or household practices on hygiene and sanitation have dual results of positive or negative health indications to the whole community as per the strategies adopted. Staying unhygienic, poor sanitation facilities and unaware of sanitation practices can lead to infectious diseases. 
The state government with the support of central government has launched and implemented various schemes, programmes and campaigns to have coverage on the above discussed issues, but many communities and areas in the study area still lack basic facilities which may because of socio- economic reasons culminated with difficult geographical location. Anini, the study area, is the district headquarters of Dibang Valley district in Arunachal Pradesh. It is located far from the neighbouring districts and towns and has harsh communication and transportation bottlenecks. Therefore, it is felt that the present research work is a well thought study that has well focused on health status and sanitation practices of the area.

To understand the relationship between health status and sanitation, the present study has focused on aspects of sanitation facilities, status, technology, hygiene practices, waste disposal, clean drinking water, local environment and awareness about sanitation of the study area.

\section{Statement of the Problem}

Health status of a person and having a proper system of sanitation is the key issue for overall human development, which is true with the tribal society of Arunachal Pradesh. Health problems of a society have proven to be the leading cause of economic degradation of the state, anxiety and social causes in the family. Improper sanitation system and mismanagement of same by the administration along with lack of societal responsibility have resulted into poor health status and prevalent of common diseases in and around Anini township of Dibang Valley district in Arunachal Pradesh.

The people of the study area especially in the Anini Township are highly affected by the improper sanitation system. Firstly, the non availability of sufficient potable water, as the ground water of the area is affected from soil pollution and secondly, the drainage system along the market line and residential colony areas are literally narrow and have no drainage system that frequently gives rise to communicable diseases.

One particular concern is pertinent and it was felt by the researcher, if who could take the responsibility to bring the change? What may happen if the problems of sanitation issues are not solved immediately? The concerns of the possibility of epidemic break out, if the sanitation issue is not mitigated properly.

Presently health status and sanitation is the growing global concern and Arunachal Pradesh with the rest of the country, by its flagship programme of Swachh Bharat Mission (SBM) has started its combing operation towards mitigating Water Sanitation \& Hygiene (WASH) campaign in the state. As per the protocol of SBM, every community must be made aware of sanitation, sanitation programme, policies, and assistance from the government to implement the sanitation programme.

Despites the constant and persistent initiation and support by the state government agencies, there is multiple breakdown in achieving the goal and Anini the study area, is no exception. The set back is also added for the factors like ignorance and lackadaisical or casual attitude by the people, which also include negligence of the operation and maintenance of the public facilities by the people. The local people lack proper information and education on sanitation and water born diseases. Additional factors like lack of knowledge on scientific and safe disposal of the excreta have led to consequence on public health issues and problem. In the wake of the above issues, the present study has sought an attempt to find out the factors that determine the deteriorating health condition of peoples in the study area of Anini and adjoining areas.

\section{Framework of the Study}


The following is the framework of the study adopted for better insight on the topic selected for the study.

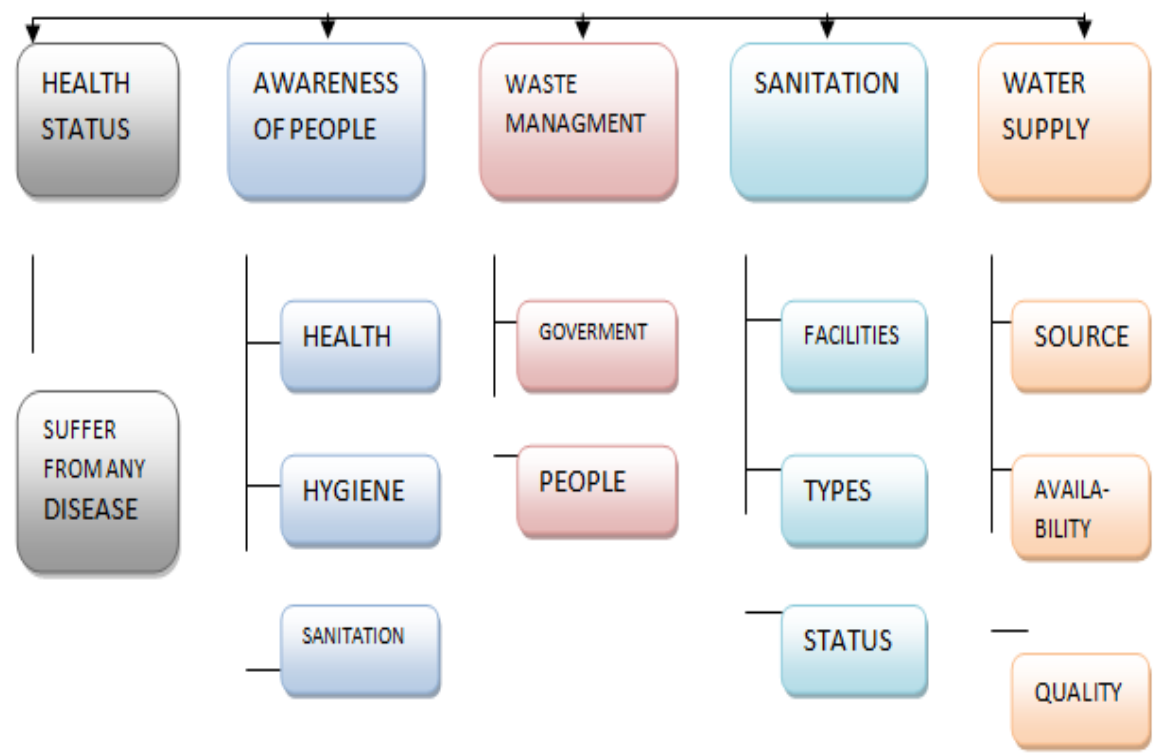

Figure 1: Framework of the Study.

Health Status \& Sanitation.

\section{Study Area}

Case study research design has been adopted for the study. To find out the answer of research questions, I have selected the Anini the headquarters of the Dibang Valley district in Arunachal Pradesh, India. Idu Mishmis, known as Yidu Lhoba in China, are the major inhabitants of the township. Anini's name may have come from the Idu word "inni" meaning the supreme deity or god for them (Wikipedia). Anini, is a plateau situated between Dri and Mathuan rivers. The district has only one sub-division namely Anini and 3 (three) CD Block with five Circles. As per 2011 Census round, the administrative set up of the district is seen in table 1(Census of India 2011 Arunachal Pradesh).

Table 1: Administrative Set Up of Dibang Valley District

\begin{tabular}{|c|l|l|l|}
\hline S. No & \multicolumn{1}{|c|}{$\begin{array}{c}\text { Name of the Sub } \\
\text { Division }\end{array}$} & Name of the CD Blocks & Name of the Circles under the CD Block \\
\hline \multirow{3}{*}{1} & \multirow{3}{*}{ Anini } & 1. Anini-Mipi & $\begin{array}{l}\text { 1. Anini } \\
\text { 2. Mipi }\end{array}$ \\
\cline { 3 - 4 } & & 2. Etalin & 1. Etalin \\
\cline { 3 - 4 } & & $\begin{array}{l}\text { 3. Anelih } \\
\text { 2. Kronli (Arzoo) }\end{array}$ \\
\hline
\end{tabular}

Source: Census of India 2011 


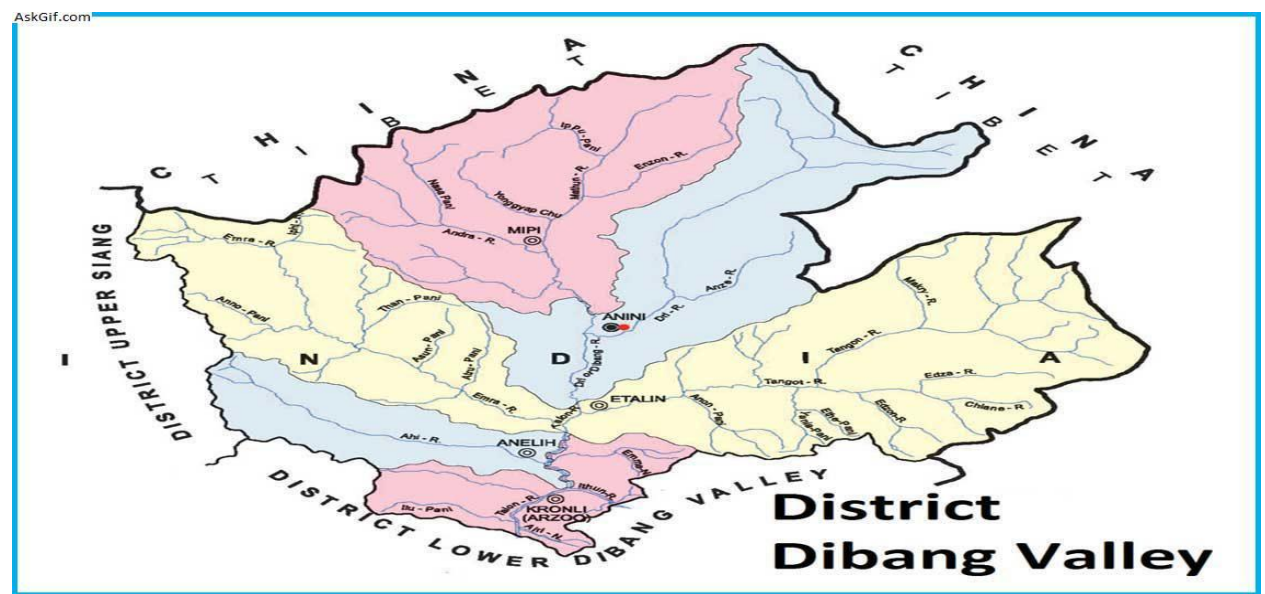

Source: AskGif.com

Figure 2: Dibang Valley District, Arunachal Pradesh.

\section{METHODOLOGY}

The total number of respondents included for the study was 105 of a total of 52 households spreading across the four major settlements and colonies namely; New Anini, Prabaya, Kaji and Old Bazaar. These four colonies included 8 household from New Anini, 27 household from Prabaya, 8 household from Kaji 9 household from Old bazaar. These household were randomly picked during the time of fieldwork.

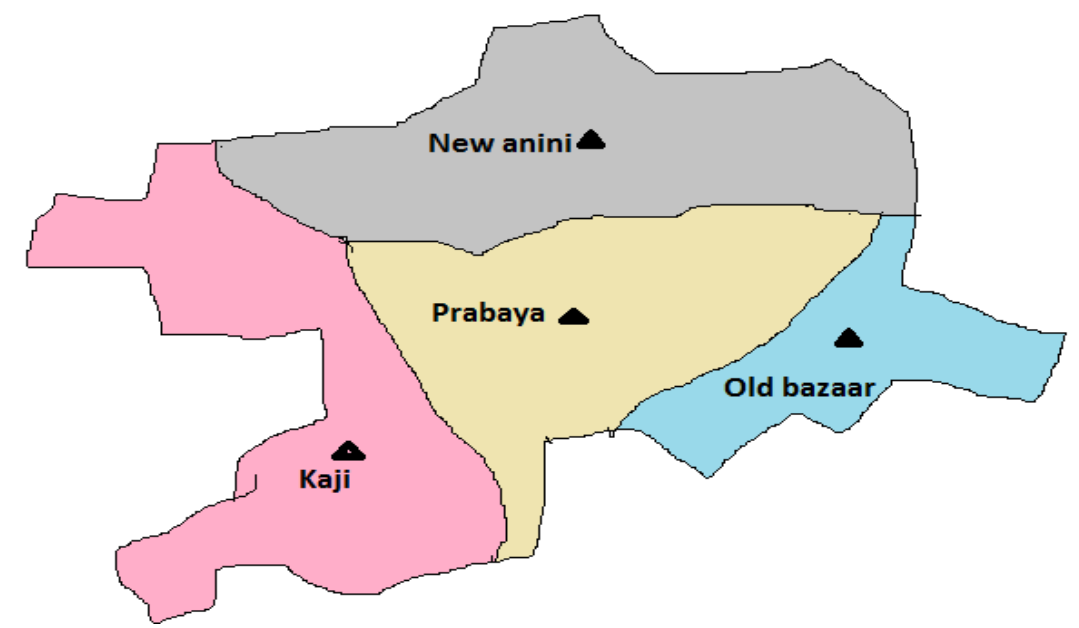

Source: Field work

Figure 3: Study Areas in Anini Township.

The primary data collection method included Interview schedule. The information was collected by interns of Department of Sociology, Rajiv Gandhi University, Arunachal Pradesh supported by the researcher. The questions to be included were prepared on various measurement scales. The data provided by each respondent were directly filled in the interview schedule during the process of interview. The analysis was done with the help of MS-Office Excel software. Few selected secondary sources like journals, newspaper and government based publications were consulted to strengthen the statement and defend the research. 


\section{FINDINGS}

The information was obtained through Interview schedule, discussion with key informants from different colonies of Anini Township. The study areas namely New Anini, Prabaya, Kaji, and Old bazaar were covered with visit to the households for the study. Various figures, tables and bar diagrams have been developed to illustrate the patterns of health, sanitation, and hygiene condition with additional information collected on status of water supply, waste management and level of awareness of people related to the topic of the study. The main findings have been classified separately and explained below.

\section{Education Level and Awareness of People}

In order to assess the level of awareness by the people on sanitation, health condition, and hygiene condition, in the study area, the educational level of 52 household have been surveyed and studied. Education is the primary tool to get solutions of every problems and for the purpose of the present study, education is supposed to help in identifying the issues of sanitation, hygiene, water supply and waste management problems by the people of the area. How far they can understand and acknowledge the basic needs of these issues lie in their pursuit of a clean environment to live a healthy life and realise on if what these facilities were not there and that would in return affect their health status.

Figure 4 shows the distribution of education level of the studied people. $47.6 \%$ of the people are literate but with lower level of schooling, as low as till secondary level as many opted to drop out due to reasons like social sanctions of early marriage, financial issues to pursue higher studies including others. $6.6 \%$ have studied till five to eight standard, $0.9 \%$ till primary level and $4.7 \%$ are illiterate. However, $37 \%$ of them have persuaded or persuading higher studies and taking up professional courses (paramedics etc.) for being more eligible while seeking job scopes. This is clearly shows that the studied population mostly are illiterate or have very less education levels but many of them too are literate enough to grasp the understand various issues surrounding them.

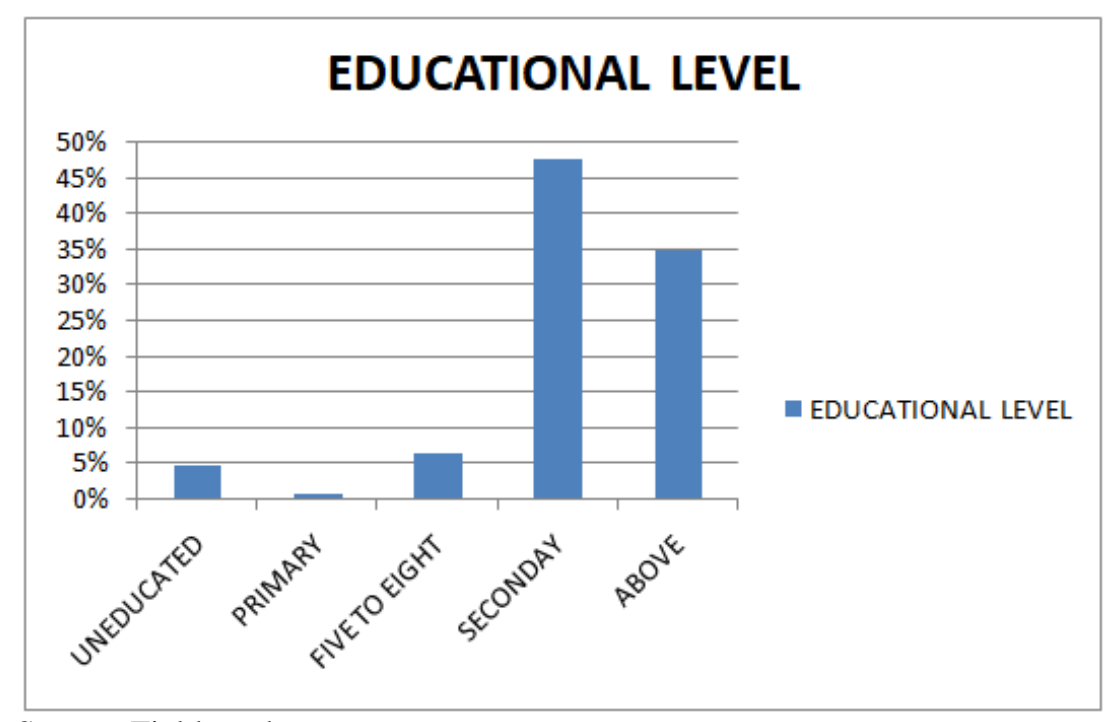

Source: Field work

Figure 4: Status of Educational Level (\%) in the Study Area.

The percentage of awareness in the community in the account of sanitation, hygiene and health are shown in figure 5. It is evident that people are both aware and unaware about sanitation, hygiene and their health condition. $78 \%$ of the respondents are aware of sanitation and know the importance to have toilet facility in a household, drainage for domestic 
waste water flow, proper disposal of excreta (however this doesn't include disposal of animal excreta). $21 \%$ of respondents are unaware of sanitation facilities. $4 \%$ of them though have toilets but the human waste flow through the connected to nearby streams that flow openly and creating environmental pollution.

The status of awareness and hygiene practice is illustrated in figure 4. While concerning awareness on hygiene, $57.14 \%$ of the respondents are aware, and $38 \%$ of them are unaware. They are not aware on the probable effects of contamination due to the toilet system they have connected to the nearby streams. Most of the people rear domestic animals, and most common of them being hen, pig and cow. People use the excreta of domesticated animals as to grow vegetables etc., but are not aware of using bare hands in handling them. It is contested that less knowledge of proper hand washing in this regard, could lead to people suffering from various infections.

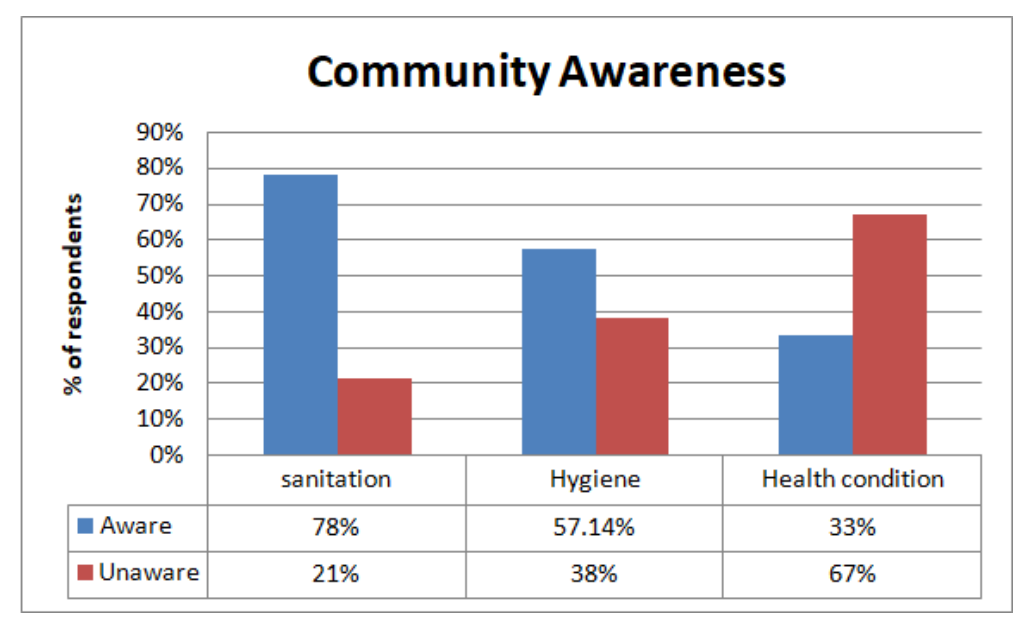

Source: Field work

Figure 5: Status of Community Awareness of Hygiene \& Sanitation.

Health status of people in the study is not much visible because of lesser awareness level of the people of their health condition. $33.3 \%$ of the respondents are aware and $67.6 \%$ of them are unaware on the issue. The awareness of community in the study area is higher on issues of sanitation and hygiene condition compared to their awareness on their respective heath condition and it is also possible that they are not well aware of water borne diseases which could lead them to spend more on health. Further it was found that people did not go for any health checkups until and unless they felt it was necessary.

\section{Health Conditions}

To study the health conditions of people, the indicator of health seeking behaviour in the terms of health check-up has been incorporated. The study found that $60 \%$ of the respondents go for health check up during health needs and it also meant that that people who were sick recovered from them. $8 \%$ of them never had any health need based health check-up in a modern facility. During the occurrence common flu or fever people availed traditional methods of treatment like home remedy, fasting, and prayers. $3 \%$ of th respondents go for health check-up once in three months, $6 \%$ once in six month and $24 \%$ once in a year as shown in figure 6. Most of these people actually suffered from major illness like tuberculosis, heart disease etc. As people are less aware of their health conditions, the status of health is not much visible. Respondents, who go for medical 
check up, once in three months, mostly had ailments like hepatitis, heart condition etc., and because of non availability of tertiary health care in the area, most of them go out of the district for medical treatment.

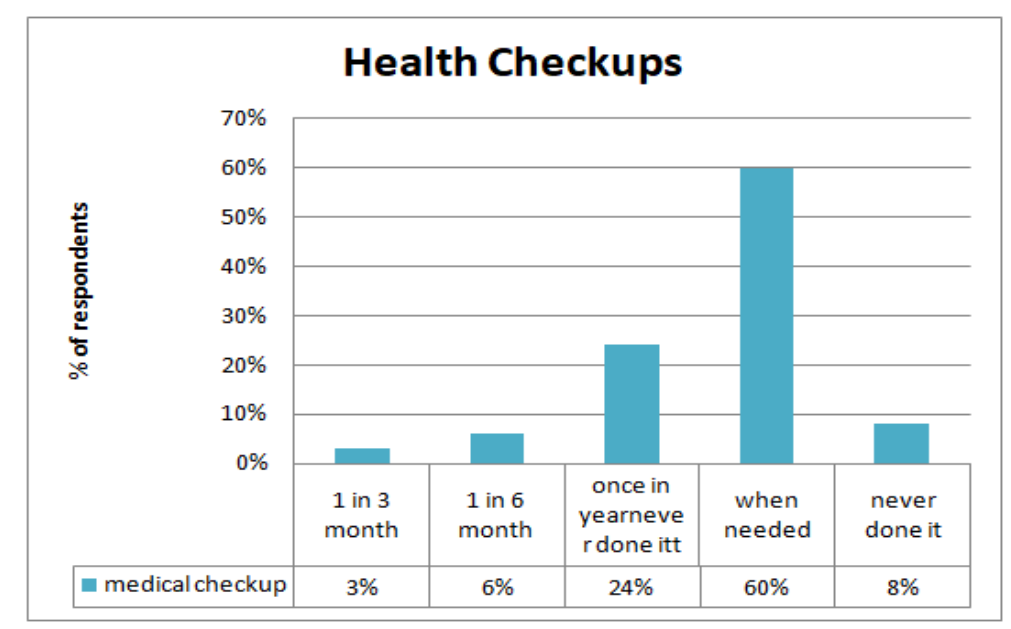

Source: Field work

Figure 6: Status of Health Checkups.

Health status and behaviour of people have been studied and the comparison is shown in figure 7 and Figure 8 , where illustration on the heath status has been done by depicting the diseases and their occurrence due to related factors of their behaviour and habits or due to water, hygiene and sanitation provisions. Figure 7 speaks of behavioural pattern of the respondents responsible for their health status. $14 \%$ of the respondents were chain smokers, $42.8 \%$ are were either alcoholic or used alcohol persistently and amazingly $0.9 \%$ of the respondents used some or the other forms of substance abuse or drugs products. With this we get to know people's health condition in the area is determined by behavioural pattern.

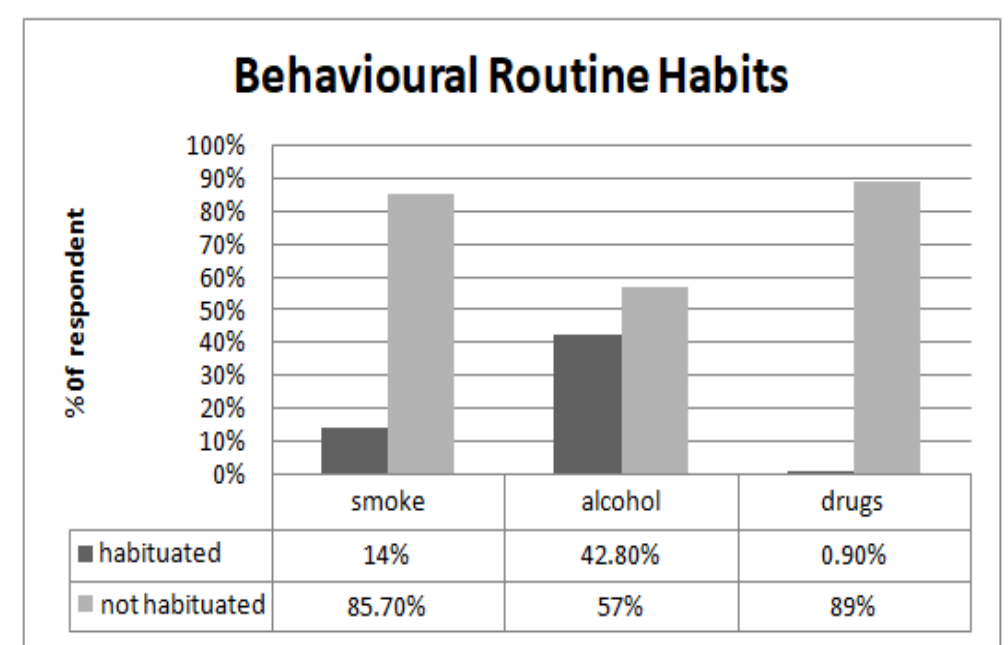

Source: Field work

Figure 7: Status of Behavioural Routine Habits.

It is found that hepatitis, malaria and typhoid are results of insanitary condition in the area. Non communicable diseases like High blood pressure, Heart disease and Diabetes are prevalent due to improper diet and by habitual behaviour of smoking and use of alcohol. Out of 105 respondents studied, 17\% have hepatitis, 2\% had malaria, 1\% had typhoid, 5.7\% 
are diabetic, $14 \%$ are hypertensive and $4.7 \%$ have heart related ill conditions. Hepatitis was the most common disease among others and this speaks volumes of water borne infection in the area.

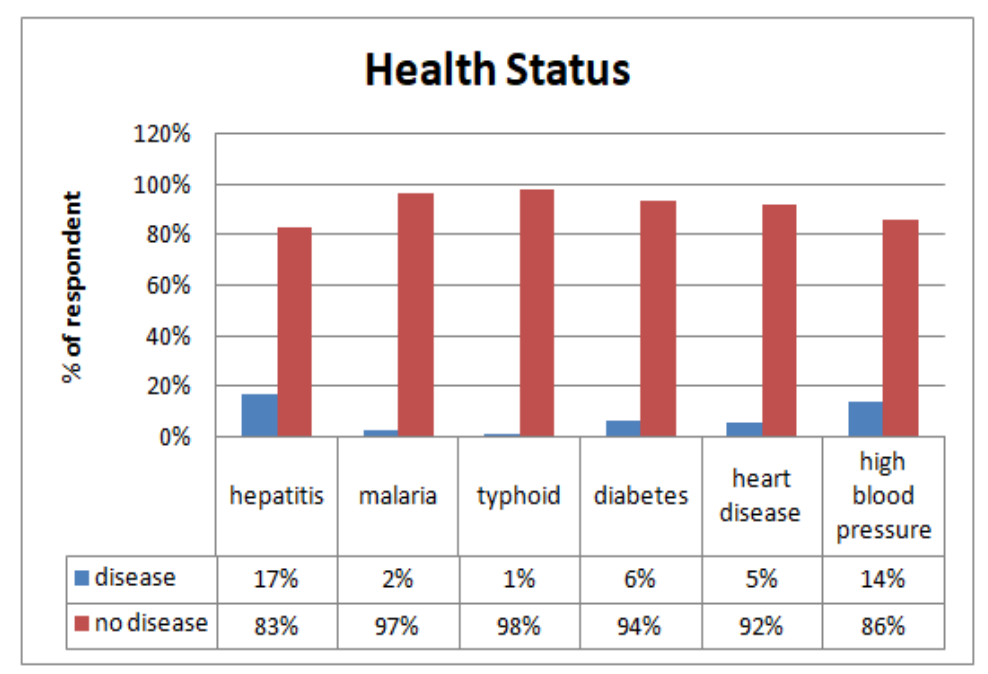

Source: Field work

Figure 8: Health Status.

\section{Hygiene Practices}

Basic hygiene practice can prevent the spread of infection caused by an organism. Cleaning process like hand wash, taking bath can remove the infectious microbes and dirt from our body. The hygiene practice of people of the study area is illustrated in table $1.4 .7 \%$ of the respondents had hand wash with soap before having meal but not after using toilet. Percentage of people washing hand after using toilet is $37 \%$ and $58 \%$ of them wash their hand before and after meal and also after using toilet.

Table 2: Status of Hand Wash \& Bathing

\begin{tabular}{|c|c|c|c|}
\hline \multicolumn{2}{|c|}{$\begin{array}{c}\text { Options } \\
\text { Washing Hand, Taking Bath }\end{array}$} & Washing Hand with Soap & Taking Bath \\
\hline Before meal & Everyday & $4.7 \%$ & $23.8 \%$ \\
\hline After using toilet & Two/three times in a week & $37 \%$ & $66.6 \%$ \\
\hline Before and after using toilet & Once in a week & $58 \%$ & $9.5 \%$ \\
\hline
\end{tabular}

To stay hygienic, people must take bath after perspiration or physical work and $23.8 \%$ (table 2) take bath regularly or every day. Percentage of respondents taking bath two to three times in week after work and playing is $66.6 \%$. Some of them felt that bathing regularly was not good for skin. $9.5 \%$ of them took bath once in week. Some of them felt that bathing was unnecessary until a person truly sweats after a physical activity.

For good health and life people must follow hygiene practices like taking bath, hand washing with soap, brushing teeth, cutting nails and keeping the surrounding clean etc. These practices can maintain their personal hygiene and keep surrounding clean. Figure 9 shows that $43 \%$ of the respondents agree to the notion that they get sick because of unhygienic practices and that such behaviour could lead to serious health issues. Whereas, $57 \%$ of them people disagreed that unhygienic practices could lead to any form of health problems as they felt that by staying clean not necessarily would confirm their status of being away from any health problems. 


\section{Sanitation}

Sanitation involves the provision and services for safe disposal of human urine and faeces that has been dealt through sanitation facilities, types and their status in the area. Figure 10 explains on the sanitation facilities in the study area.

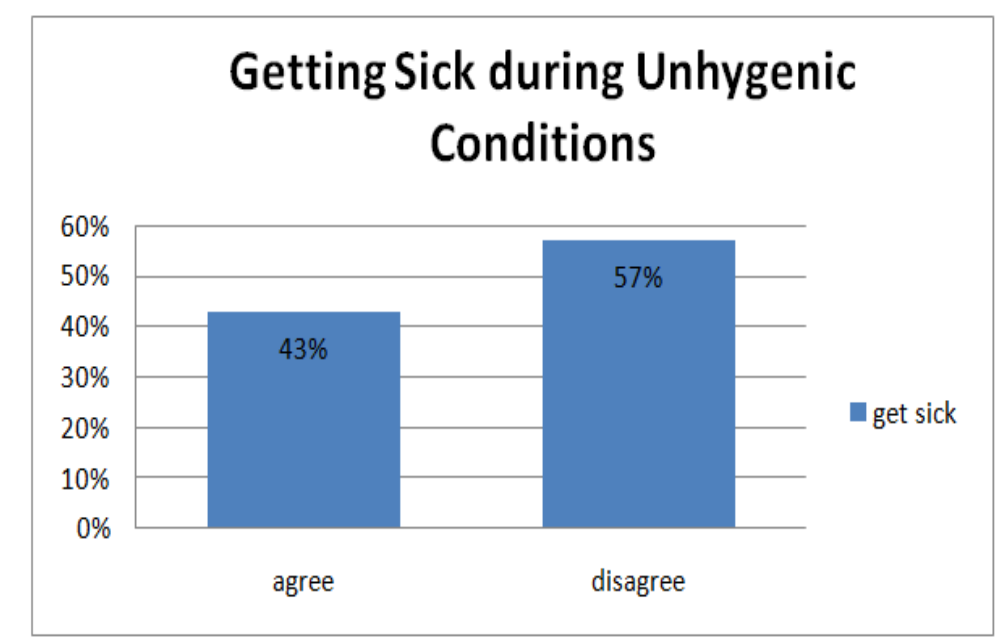

Source: Field work

Figure 9: Status of Getting Sick during Unhygienic Conditions.

$84 \%$ of the household have sanitation facilities and $15 \%$ of household do not have any toilet facilities, for some of the household did not have sufficient space to build toilet and that they shared the same with their neighbour. $15 \%$ of them shared their toilets with others and $84 \%$ of them had their independent toilets. The household who share their toilet were mostly built with bamboo that was connected by pit and runnel to dispose faeces.

$89 \%$ of household had pit toilets and $9.5 \%$ toilets were connected with the river or runnel made of bamboo and pucca toilet and the faeces normally flowed in open area causing pollution in the environment. $3.8 \%$ of the respondents use other type of toilet like pour flush toilet and bamboo framed toilet that are connected with pit and septic tank. 3.8\% household have separate toilets on the basis of gender. Though people are aware of their toilet requirements but their practice could not match up to the actual need of proper disposal.

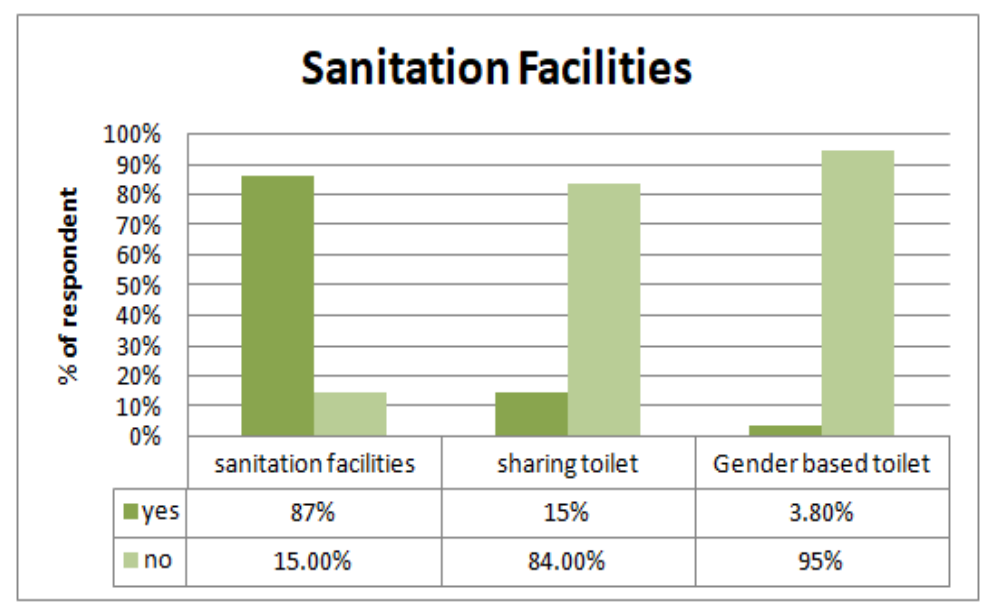

Source: Field work

Figure 10: Status of Sanitation Facilities. 


\section{Sanitation Status}

Figure 11 explains on the status of sanitation practices and facilities that are shared by the household members. Percentage of cleaning toilets in the following bar graph show that $70 \%$ of people clean their toilets every day, and $17 \%$ clean their toilets three times in week and $8.5 \%$ clean them sometimes only when the toilet is supposedly not clean enough to use.

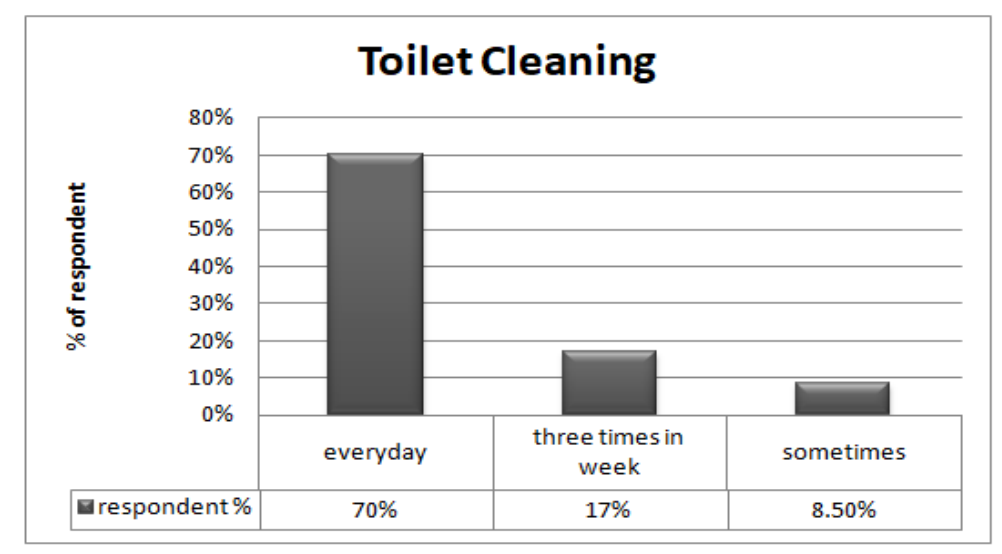

Source: Field work

Figure 11: Status of Cleaning Toilet.

Some toilets were in depilated and dirty conditions because of unawareness of respondents on infections that could likely occur due to insanitary condition resulting to diseases like malaria, typhoid, and other infections. According to the data collected, $8.5 \%$ respondents who clean their toilets sometime are mostly school dropout having lesser knowledge on hygiene and sanitation. However, most of the toilets in the study are in sanitary condition which is good for healthy life.

\section{Waste Management}

Waste management includes safe disposal and streamlining of solid wastes, stagnant water, drainage system and disposal of human faeces. In the study area waste is managed by the state government through its nodal agency i.e., Urban Development and Housing department and voluntarily by the community. The weekly collection of garbage by the department is shown in figure 12 .

According to respondents, urban department collects garbage from street dustbins and piled up wastes in the colonies.

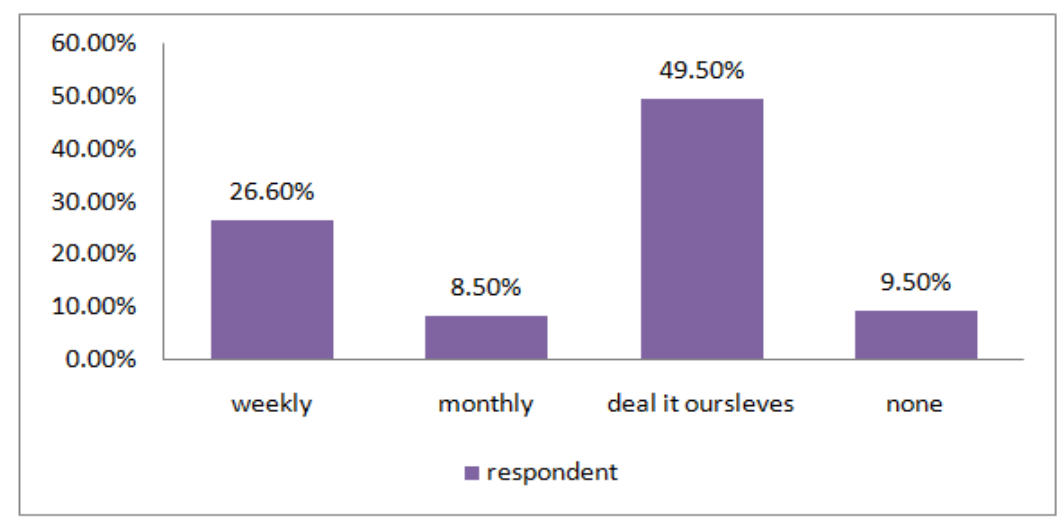

Source: Field work

Figure 12: Status of Waste Management by Urban Development Dept. 
$26.6 \%$ of respondents agreed that the waste were collected on weekly basis and $8.5 \%$ agreed that it was done on monthly basis by the department. The community involvement shows that, $49.5 \%$ of the wastes management or collection is done by individuals themselves. It was informed that the concerned department collects wastes only from areas like Prabaya, old bazaar and new Anini but not from Kaji. People are not satisfied with the service of urban department waste management system and process.

Further, it was found that people themselves managed such unattended wastes and garbage by putting them in dustbin(43.80\%), burning them(34\%) and collecting and burning them(19\%) as shown in so they dealing it themselves it shown in figure 13.

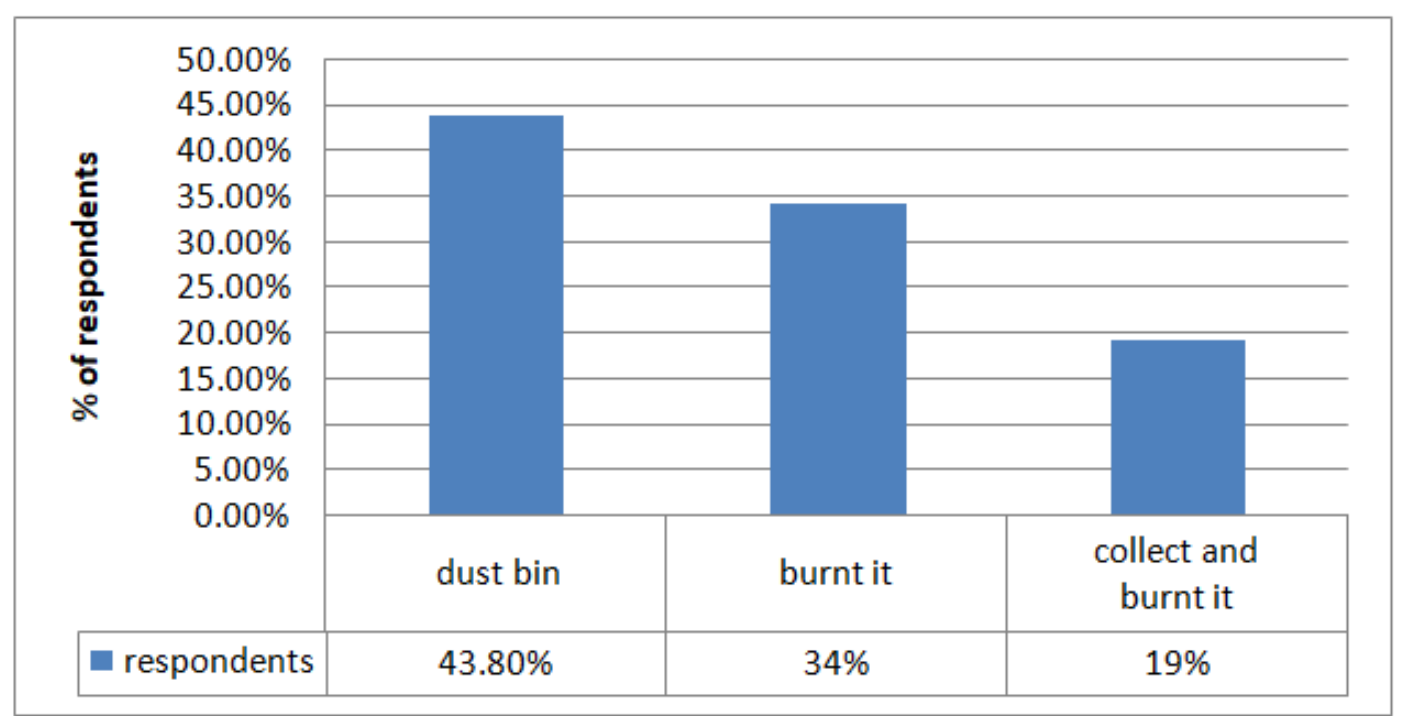

Source: Field work

Figure 13: Status of Waste Disposal by People.

People deal with the waste by collecting and burning them and some collect and disposing them in the dustbin. Others collect the waste from domestic and local surrounding and dispose them in street dust bins and dumping areas identified by the community. However, due to burning of large quantity of wastes and garbage have led to probable illnesses in the community.

\section{Water Supply}

Water is the most essential and basic ingredient for any effort towards a hygienic and sanitised environment. Inadequate water supply adds to poor sanitation thereby paving for numerous infections in the community. Most of the household have water supply from government distribution system through department of Public Health Engineering. 93\% of the household use water tank connected to their houses, $4 \%$ of them use river water by connecting pipe to the river, $2 \%$ fetch water form River and $1 \%$ of them use other sources of water supply. Figure 14 illustrates the sources of water supply, availability of water and quality of water in the study area. 


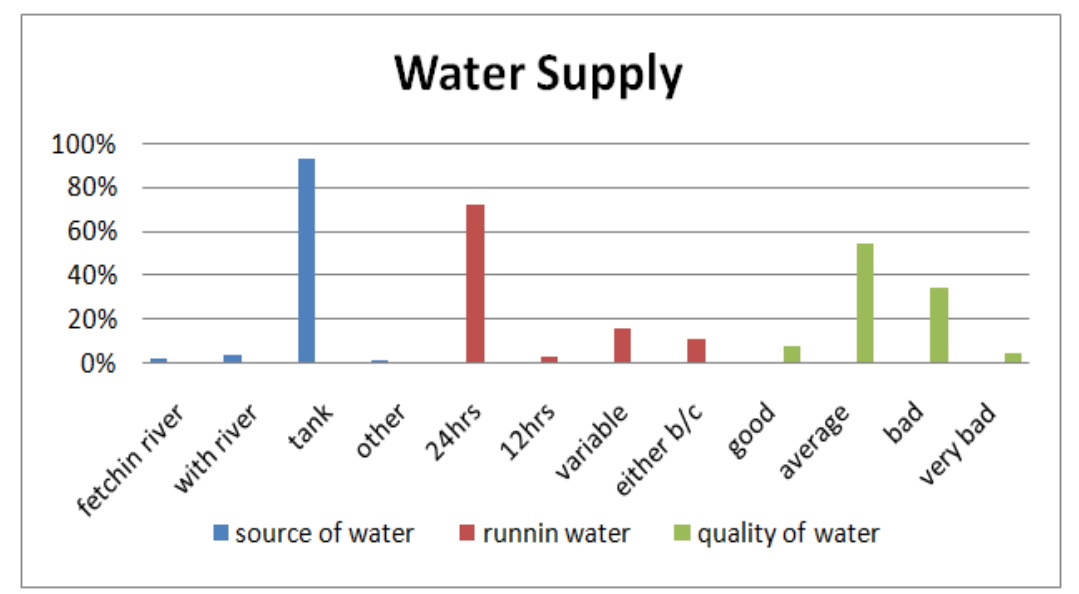

Source: Field work

Figure 14: Status of Water Supply.

$72 \%$ of household have $24 \mathrm{hrs}$ running water, $2 \%$ household receive water for $12 \mathrm{hrs}$ in a day, $15 \%$ of household faced water variables and $10 \%$ of household have either $24 \mathrm{hrs}$ running water or variables in water supply often. The household who receive $24 \mathrm{hrs}$ water supplies have average quality of water. $7.6 \%$ of household receive good quality of water, $54 \%$ of them receive average quality of water, $34 \%$ receive bad quality of water, and $3.8 \%$ receive very poor quality of water. When heavy rainfall occurs average quality of water gets converted to extremely poor quality water, which is normally not advisable for daily domestic consumption.

\section{EXECUTIVE SUMMARY}

The study found that health status of people is determined by their habituated behaviour and also by the status of sanitation, hygiene and water supply in their community. It was found that people are unaware of their health condition as $8 \%$ of them never availed any form of health check-up and $61 \%$ of them go for health check-up only when it is either felt important or it is too late. People are aware of using toilets and sanitation facilities which is evident from their practice of sharing their toilets rather than defecating in odd places. However, most of the toilets being shared were in insanitary conditions that prompted for water borne disease and infections the reason being either the issue owning the toilets or due to casual attitude of the users. Gender based toilet are normally allocated in government of public institution or work place, however as per the outcome it was found that such toilets are essential in households too.

Waste management done by government department lacked manpower and disposing vans. The collection of garbage from the designated places and street dust bin were poorly managed. It was observed that many places were seen with piled up garbage for several days during the process of research visits. This also has led the community to own the responsibility in volunteering themselves for the clearing of wastes. Due to burning of wastes, toxic smoke along with a foul smell resulted into lung ailments and environmental pollution. The behavioural pattern of people have led to ailments that needed in-depth interventions in tertiary care hospitals which is absent in Anini township, thereby forcing people to go outside their dwelling place involving lot of expenditure on health care.

Most of the household have government water supply, but some of them still fetch untreated water from streams and rivers that may be contaminated and not healthy for consumption. The government run services that provide sufficient water but it was found that the water was not of good quality and during monsoon the quality went worse. This poor quality 
of water released is untreated and were found to be turning into brown or black full of sediments. This is the reason that $17 \%$ of people are suffering from hepatitis.

\section{SUGGESTIONS}

Based on findings, the following suggestions are being made;

- Mass awareness must be generated wisely to remind people about sanitation, hygiene. People need to be made aware of routine health check up to update their health condition.

- Natural water source must be tapped and protected well for public distribution. Strict norms should be adopted to provide treated water to the households.

- Government must provide and adopt mandatory measures and to cover all household in the study area to have sanitation facilities with proper disposal of faeces and other household wastes.

- Wastes should be collected from all the township areas periodically with strict monitoring of carriage.

- Waste disposals should be done far from human settlements with latest technical support.

\section{REFERENCES}

1. Abul A. Masrur, Masrur Ahmed, Jahir Bin Alam 2010. Hygiene: Case Study of Slums in Sylhet. Kathmandu Evaluation of Sanitation, Nepal.

2. Ashish Saxena 2013. Sociology of Sanitation, New Delhi.

3. B. K. Nagla 2015. Sociology of Sanitation, Kalpaz Satyawati nagar, Delhi.

4. Census of India 2011, Arunachal Pradesh, Series-13 Part XII- A District Census Handbook, Dibang Valley, Village and Town Directory, Directorate of Census Operations, Arunachal Pradesh.

5. D. Nanam, F. White, l.azam, H. Afsar, S. Hozhabi 2003. Evaluation of a Water, Sanitation and Hygiene Education Intervention.

6. Nitin Bajirao Borse 2015. Impact of Housing Condition and Sanitation on Health Status.

7. Mara D, Lave J, Scott B, Trouba D. 2010. Sanitation and Health, plosmed 7 (ll):el000363.Doi:10.1371/Journal.pmed.100036

8. Okanya Arinzechuku, Nicolas Valcourt, Amy Javermick Will, Jeffery Walters, Karl Linden 2020. System Approaches to Water, Sanitation and Hygiene. Basel, Switzerland.

9. Toochuku Nwakile 2010. Sanitation Practice of Student Health. https://ijmer.com

10. Pesala Burenna and M. Snehalath 2013. Water, Sanitation and Hygiene Practices in Rural India. https://ssm.com/abstract=2437399

11. Sandy Cairncross 2003. Editorial: water supply and sanitation: some misconceptions, London.

12. Sital Uprety, Nora Sadik, Bipin Dangol \& Thanh H. Nyuyen 2017. A quality case study of Water, Sanitation and Hygiene resources after Gorkha earthquake in Nepal. https://www.researchgate.net/publication

13. Taylor \& Francis 2014. Water, Sanitation and Hygiene and Indigenous people: a review of the literature. https:/doi.org/10.1080/02508060.2014.903453.

14. WHO 2005. Sanitation and Hygiene Promotion, 1219 Chatelaine Geneva, Switzerland. 
